\title{
Study of Dropwise Condensation on Teflon Coated Surface
}

\author{
M.D.Kulkarni ${ }^{1}$, P.L.Puthani ${ }^{1}$, A.T.Patil ${ }^{1}$ \\ Asst. Professor, Mechanical Engineering, BLDEA's V P Dr.P.G.H.College of Engg. \& Tech., Vijayapur, India ${ }^{1}$
}

\begin{abstract}
The paper reviews progress in dropwise condensation research from 1930 to the present. An experimental investigation has been performed in which promotion of dropwise condensation of water vapors is achieved by coating a bare iron tube with polytetyrafluoroethylene (Teflon). Experimental Overall heat transfer coefficients are presented for the dropwise condensation of water vapors on the Teflon coated tube and for filmwise condensation on the bare iron tube. The overall heat transfer coefficients obtained for dropwise condensation on Teflon coated tube is approximately 20 to 60 percent more for water than those for filmwise condensation on bare tube.
\end{abstract}

Keywords: Dropwise condensation, filmwise condensation, Teflon, Overall heat transfer coefficient.

\section{NOMENCLATURE:}

$\mathrm{Q}$ - Heat flow rate $(\mathrm{W})$

$\mathrm{U}$ - Overall heat transfer coefficient $\left(\mathrm{W} / \mathrm{m}^{2 \circ} \mathrm{C}\right)$

$\Delta \mathrm{T}$ - Change in temperature $\left({ }^{\circ} \mathrm{C}\right)$

$\mathrm{T}_{1}-$ Steam inlet temperature $\left({ }^{\circ} \mathrm{C}\right)$

$\mathrm{T}_{2}$ - Water inlet temperature $\left({ }^{\circ} \mathrm{C}\right)$

$\mathrm{T}_{3}$ - Water outlet temperature $\left({ }^{\circ} \mathrm{C}\right)$

$\mathrm{T}_{4}$ - Steam outlet temperature $\left({ }^{\circ} \mathrm{C}\right)$

$\mathrm{T}_{\text {sat }}$ - Saturation temperature $\left({ }^{\circ} \mathrm{C}\right)$

$\mathrm{T}_{\mathrm{s}^{-}}$- Surface temperature $\left({ }^{\circ} \mathrm{C}\right)$

$\mathrm{A}_{\mathrm{s}}$ - Surface Area $\left(\mathrm{m}^{2}\right)$

$\mathrm{C}_{\mathrm{p}}$-Specific heat $\left(\mathrm{cal} / \mathrm{kg}^{\circ} \mathrm{C}\right)$

\section{ABBREVATIONS:}

LMTD - Logarithmic Mean Tempearture Difference PVC- Poly Vinyl Chloride

PTFE- POLYTETRAFLUROETHYLENE

\section{INTRODUCTION}

Condensation occurs when the temperature of a vapor is reduced below its saturation temperature $\mathrm{T}_{\text {sat. }}$ This is usually done by bringing the vapor in contact with a solid surface whose temperature $T_{\mathrm{s}}$ is below the saturation temperature $T_{\text {sat }}$ of the vapor. But condensation can also occur on the free surface of a liquid or even in a gas when the temperature of the liquid or the gas to which the vapor is exposed is below $\mathrm{T}_{\text {sat }}$.

In the later case, the liquid droplets suspended in the gas form a fog. Two distinct forms of condensation are observed: filmwise condensation and drop wise condensation. In film condensation, the condensate wets the surface and forms a liquid film on the surface that slides down under the influence of gravity. The thickness of the liquid film increases in the flow direction as more vapors condense on the film.

This is how condensation normally occurs in practice. In drop wise condensation, the condensed vapor forms droplets on the condensing surface instead of a continuous film, and the surface is covered by countless droplets of varying diameters [1].

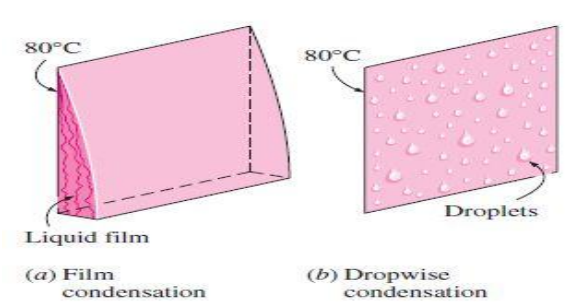

Fig.1.1 Filmwise and Dropwise condensation

Little is understood about the mechanism of dropwise condensation or the associated heat-transfer process, except that heat-transfer rates are 2 to 10 times those for filmwise condensation for the same temperature difference [2]. Commercially, it is difficult to predict whether dropwise condensation will occur and difficult to maintain it for long periods of time. No known ordinary metallic surface, when clean, will produce dropwise condensation.

To obtain dropwise condensation, metallic surfaces must be coated with a film of some substance that the liquid does not wet, or a suitable promoter may be injected into the condenser with the incoming vapor. Some promoters of dropwise condensation are the fatty acids, light hydrocarbon oils, and waxes. However, promoters of this type wash off the condensing surfaces rather quickly and usually last only for periods of several seconds or, in some rare cases, up to a maximum of several hundred hours [3, 4]. Promotion of dropwise condensation is therefore desirable for increasing the effectiveness of condensing systems.

However, because of the difficulty in predicting and maintaining dropwise condensation, such equipment is presently designed on the assumption that filmwise condensation will exist [5]. Improvements in prediction techniques and development of a permanent promoter which may permit the design of condensers based on the occurrence of dropwise condensation are therefore highly desirable.

The purpose of this paper is to show that dropwise condensation of water vapors can be achieved by coating the condensing surface with a thin layer of Teflon and to 
present data on the resulting increase in the overall heattransfer coefficients compared with those for filmwise condensation.

\section{EXPERIMENTAL SET UP AND PROCEDURE}

The schematic of the experimental setup is as shown in the Fig. 2.1. The setup consists of a borosilicate glass tube of diameter 2.5 inches and length 22 inches. The tube is covered with two square glass plates of side 4 inches. These glass plates are provided with concentric holes at their centres in order to facilitate changing of specimen tubes with 1 inch diameter and 25 inches length and $1 \mathrm{~mm}$ thickness [6].

Two iron tubes are used. One is coated with a uniform thickness of polytetrafluroethylene on the exterior surface and other is uncoated. Teflon is selected as coating material for the tube. It has also been used by others to promote dropwise condensation [7, 8].

The glass plates are also provided with small holes attached with nozzle to get the steam inside the tube. The valves, PVC pipes and the direction control valves are connected as shown in the Fig. 2.1, so that the setup can be used as a heat exchanger. Provisions are made at appropriate positions for the thermocouples to detect the temperatures of the fluids.

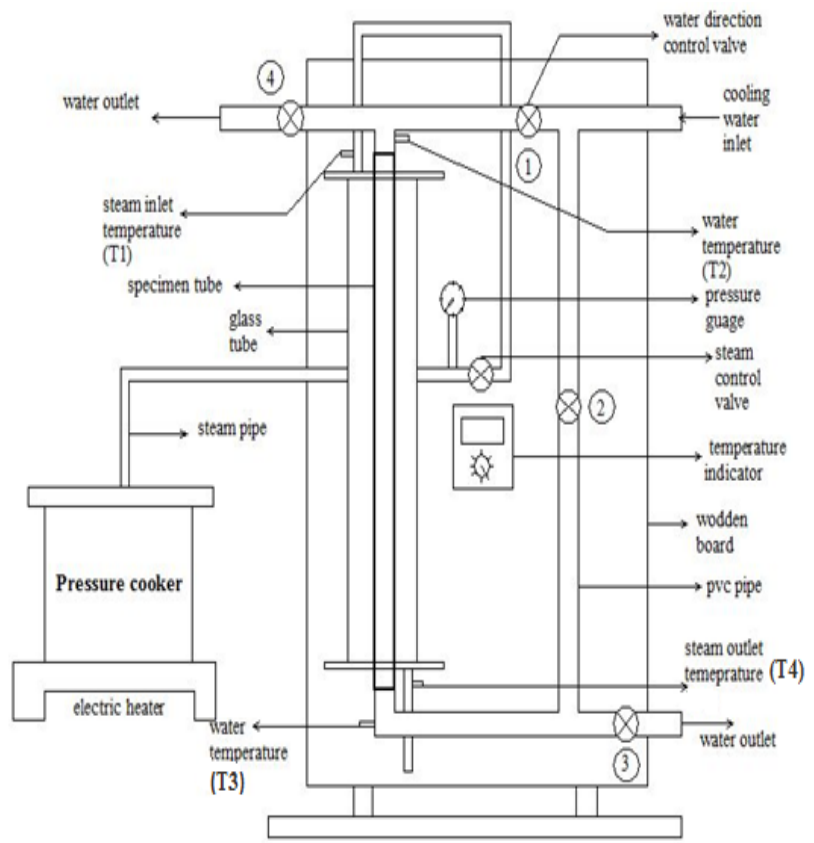

Fig. 2.1 Schematic Diagram of the Experimental setup

These thermocouples are connected to the temperature indicator. The steam is generated in a pressure cooker using an electric heater. The generated steam is released into the glass tube using the steam control valve, then the pressure gauge indicates some positive pressure of steam in the cooker. The condensate obtained is drained out at the bottom of the glass tube. The steam pipe is insulated to lower the heat losses.

The actual set up of the experiment with Teflon coated tube inside is shown in Fig. 2.2.

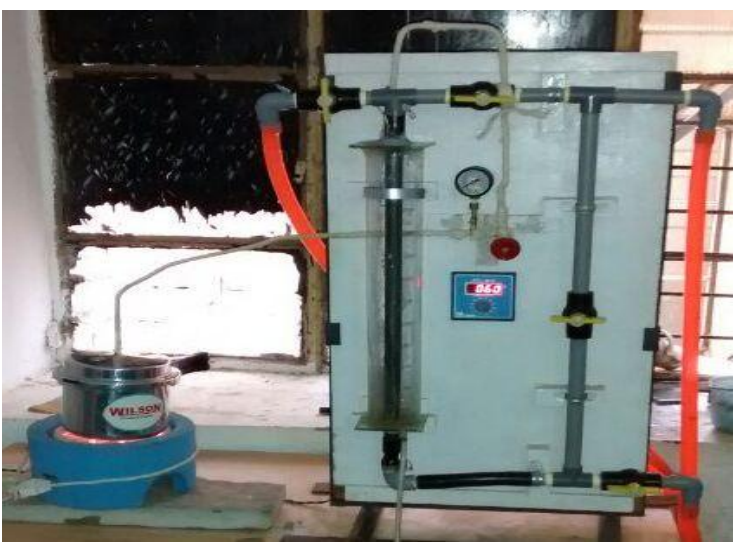

Fig. 2.2 Actual Experimental set up with Teflon Coated Tube

Before switching on the electric heater to generate steam, it is important to first adjust the flow rate of cooling water to the required level. The flow rate should be such that the condensation occurring on the surface of the specimen tube should be visible and this flow rate should be kept constant for every reading. Once the cooling water flow rate is adjusted the electric heater is switched on and the steam control valve is kept closed until the pressure gauge indicates some positive pressure (20-30 lb/inch $\left.{ }^{2}\right)$ developed in pressure cooker. Once the positive pressure is indicated the steam control valve is fully opened. The system is allowed to attain steady state and then the thermocouple readings at the appropriate positions are noted down. The steam inlet and outlet temperatures are $T_{1}$ and $T_{4}, T_{2}$ and $T_{3}$ are cooling water inlet and outlet temperatures respectively. The calculations are carried out to find the overall heat transfer coefficients for each case. Further the procedure is repeated at different flow rates of cooling water on both uncoated and PTFE coated tubes.

\section{READINGS AND CALCULATIONS}

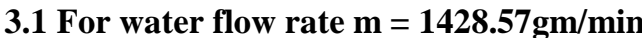

Table 3.1.1 Bare Tube readings

\begin{tabular}{|c|c|c|c|c|c|}
\hline $\mathrm{T}_{1}$ & $\mathrm{~T}_{4}$ & $\mathrm{~T}_{2}$ & $\mathrm{~T}_{3}$ & $\mathrm{Q}$ & $\mathrm{U}$ \\
\hline 94 & 45 & 37 & 43 & 597.75 & 816.22 \\
\hline
\end{tabular}

i) $\mathrm{LMTD}=\left(\left(\mathrm{T}_{1}-\mathrm{T}_{2}\right)-\left(\mathrm{T}_{4}-\mathrm{T}_{3}\right)\right) / \ln \left(\left(\mathrm{T}_{1}-\mathrm{T}_{2}\right) /\left(\mathrm{T}_{4}-\mathrm{T}_{3}\right)\right)$

$=((94-37)-(45-43)) / \ln ((94-37) /(45-43))$ $=16.42{ }^{0} \mathrm{C}$

ii)Change in water temperature

$$
\begin{aligned}
\Delta \mathrm{T} & =\mathrm{T}_{3}-\mathrm{T}_{2} \\
& =43-37=6{ }^{0} \mathrm{C}
\end{aligned}
$$

iii) Heat absorbed by water

$$
\begin{aligned}
\mathrm{Q}= & \mathrm{mC}_{\mathrm{p}} \Delta \mathrm{T}=1428.57 \times 1 \times 6 \times 60 \\
& =514285.2 \mathrm{cal} / \mathrm{hr} \\
& =597.75 \mathrm{~W}
\end{aligned}
$$

Since $(1 \mathrm{cal} / \mathrm{hr}=0.0011623 \mathrm{~W})$

iv) Surface area of condenser tube

$$
\begin{aligned}
\mathrm{A}_{\mathrm{s}} & =\pi \mathrm{DL}=\pi \times 2.54 \times 22 \times 2.54 \\
& =446 \times 10^{-4} \mathrm{~m}^{2}
\end{aligned}
$$


v) Overall heat transfer coefficient

$$
\begin{aligned}
\mathrm{U} & =\mathrm{Q} /\left(\mathrm{A}_{\mathrm{s}} \mathrm{LMTD}\right) \\
& =597.75 /\left(446 \times 10^{-4} \times 16.42\right) \\
& =816.22 \mathrm{~W} / \mathrm{m}^{2 \circ} \mathrm{C}
\end{aligned}
$$

Table 3.1.2 Teflon Coated Tube Readings

\begin{tabular}{|c|c|c|c|c|c|}
\hline $\mathrm{T}_{1}$ & $\mathrm{~T}_{4}$ & $\mathrm{~T}_{2}$ & $\mathrm{~T}_{3}$ & $\mathrm{Q}$ & $\mathrm{U}$ \\
\hline 94 & 50 & 36 & 47 & 1095.88 & 1323.17 \\
\hline
\end{tabular}

i) $\mathrm{LMTD}=\left(\left(\mathrm{T}_{1}-\mathrm{T}_{2}\right)-\left(\mathrm{T}_{4}-\mathrm{T}_{3}\right)\right) / \ln \left(\left(\mathrm{T}_{1}-\mathrm{T}_{2}\right) /\left(\mathrm{T}_{4}-\mathrm{T}_{3}\right)\right)$ $=((94-36)-(50-47)) / \ln ((94-36) /(50-47))$ $=18.58{ }^{0} \mathrm{C}$

ii) Change in water temperature

iii) Heat absorbed by water

$$
\begin{aligned}
\Delta \mathrm{T} & =\mathrm{T}_{3}-\mathrm{T}_{2} \\
& =47-36=11^{\circ} \mathrm{C}
\end{aligned}
$$

$$
\begin{aligned}
\mathrm{Q}= & \mathrm{mC}_{\mathrm{p}} \Delta \mathrm{T}=1428.57 \times 1 \times 11 \times 60 \\
& =942856.2 \mathrm{cal} / \mathrm{hr} \\
& =1095.88 \mathrm{~W}
\end{aligned}
$$

Since $(1 \mathrm{cal} / \mathrm{hr}=0.0011623 \mathrm{~W})$

iv) Surface area of condenser tube

$$
\begin{aligned}
\mathrm{A}_{\mathrm{s}} & =\pi \mathrm{DL}=\pi \times 2.54 \times 22 \times 2.54 \\
& =446 \times 10^{-4} \mathrm{~m}^{2}
\end{aligned}
$$

v) Overall heat transfer coefficient

$$
\begin{aligned}
\mathrm{U} & =\mathrm{Q} /\left(\mathrm{A}_{\mathrm{s}} \mathrm{LMTD}\right) \\
& =1095.88 /\left(446 \times 10^{-4} \times 18.58\right) \\
& =1323.17 \mathrm{~W} / \mathrm{m}^{2} \mathrm{C}
\end{aligned}
$$

\subsection{For water flow rate $\mathrm{m}=1000 \mathrm{gm} / \mathrm{min}$}

Table 3.2.1 Bare Tube readings

\begin{tabular}{|c|c|c|c|c|c|}
\hline $\mathrm{T}_{1}$ & $\mathrm{~T}_{4}$ & $\mathrm{~T}_{2}$ & $\mathrm{~T}_{3}$ & $\mathrm{Q}$ & $\mathrm{U}$ \\
\hline 95 & 53 & 37 & 48 & 767.11 & 795.55 \\
\hline
\end{tabular}

Table 3.2.2 Teflon Coated Tube Readings

\begin{tabular}{|c|c|c|c|c|c|}
\hline $\mathrm{T}_{1}$ & $\mathrm{~T}_{4}$ & $\mathrm{~T}_{2}$ & $\mathrm{~T}_{3}$ & $\mathrm{Q}$ & $\mathrm{U}$ \\
\hline 95 & 72 & 37 & 57 & 1394.76 & 982.46 \\
\hline
\end{tabular}

3.3 For water flow rate $\mathrm{m}=714.28 \mathrm{gm} / \mathrm{min}$

Table 3.3.1 Bare Tube Readings

\begin{tabular}{|c|c|c|c|c|c|}
\hline $\mathrm{T}_{1}$ & $\mathrm{~T}_{4}$ & $\mathrm{~T}_{2}$ & $\mathrm{~T}_{3}$ & $\mathrm{Q}$ & $\mathrm{U}$ \\
\hline 94 & 55 & 35 & 46 & 547.93 & 462.03 \\
\hline
\end{tabular}

Table 3.3.2 Teflon Coated Tube Readings

\begin{tabular}{|c|c|c|c|c|c|}
\hline $\mathrm{T}_{1}$ & $\mathrm{~T}_{4}$ & $\mathrm{~T}_{2}$ & $\mathrm{~T}_{3}$ & $\mathrm{Q}$ & $\mathrm{U}$ \\
\hline 94 & 64 & 35 & 53 & 896.62 & 699.50 \\
\hline
\end{tabular}

\section{RESULTS AND DISCUSSIONS}

Good dropwise condensation is observed on the top of the tube nearest the vapor-inlet end of the condenser as shown in Fig.4.1. The quality of dropwise condensation decreases at the bottom of the tube.

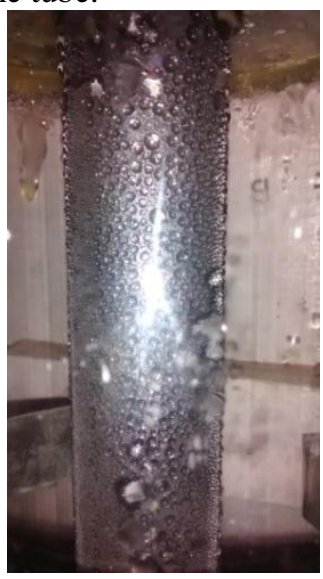

Fig. 4.1 Dropwise Condensation on Teflon Coated Tube

From the experimental results, it is clear that the rate of heat transfer and overall heat transfer coefficient has increased in Teflon coated tube compared with the bare tube. This is mainly due to sustaining dropwise on Teflon coated tube. The below Fig. 4.2 shows the condensation on bare tube, where the film wise condensation is predominant.

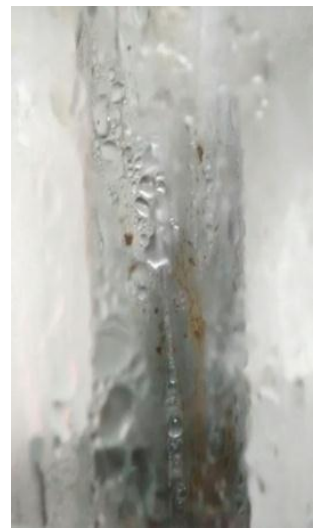

Fig. 4.2 Filmwise Condensation on Bare Tube

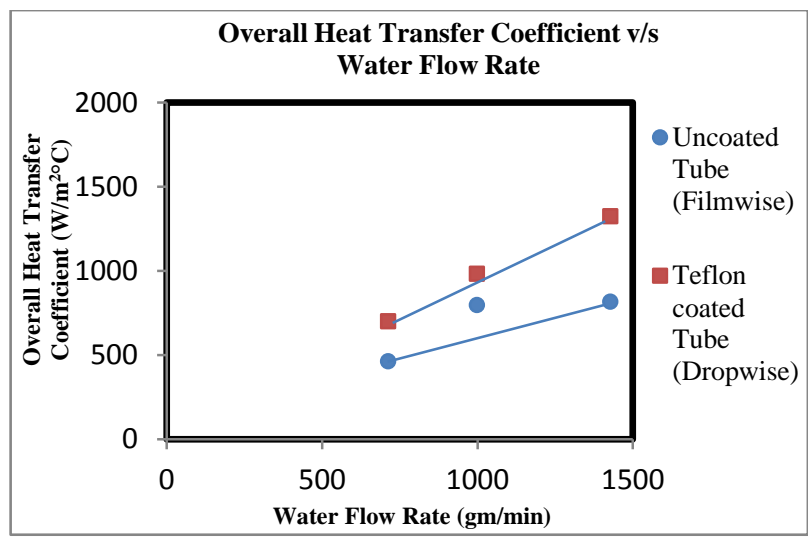

Fig. 4.3 Overall Heat Transfer Coefficient as a Function of Water Flow Rate

The overall heat transfer coefficients for water at various flow rates are shown in Fig. 4.3. The overall heat transfer coefficients increases with the flow rate. The overall heat transfer coefficients obtained for dropwise condensation 
on Teflon coated tube are approximately 20 to 60 percent more for water than those for filmwise condensation on bare tube.

\section{CONCLUSION}

Experimental overall heat-transfer coefficients are presented for the dropwise condensation of water on a Teflon-coated tube and for filmwise condensation on a bare tube. Since even in the case of dropwise condensation, a film covers the lower portion of the tube. By observing these results and the images one can conclude that the overall heat transfer coefficient and hence the heat transfer rate can be increased using the Teflon coated surfaces because of the sustained dropwise condensation occurring on the condensing surface. The overall heat transfer coefficients obtained for dropwise condensation on Teflon coated tube are approximately 20 to 60 percent more for water than those for filmwise condensation on bare tube.

\section{REFERENCES}

[1] Yunus Cengel Heat Transfer: A Practical Approach 2nd Edition, McGraw-Hill Book Co., Inc

[2] McAdams, William H.: Heat Transition. Third ed., McGraw-Hill Book Co., Inc.,

[3] Watson, R. G. H.; Birt, D. C. P.; Honour, C. W.; and Ash, B. W.: Promotion of Dropwise Condensation by Montan Wax. I. Heat Transfer Measurements. J. Appl. Chem., vol. 12, Dec. 1962, pp. 539-546

[4] Blackman, L. C. F.; Dewar, M. J. S.; and Hampson, H.: An Investigation of Compounds Promoting Dropwise Condensation of Steam. J. Appl. Chem. vol. 7, pt. 4, Apr. 1957, pp. 160-171.

[5] Rohsenow, Warren M.; and Choi, Harry Y.: Heat, Mass, and Momentum Transfer. Pr entice - Hall , Inc ., 1961.

[6] Ceil E. Kirby: Promotion of Dropwise Condensation of Ethyl alcohol, Methyl alcohol, and Acetone by Polytetrafluroethylene, Langley Research centre Hampton, Va 23365, 1971

[7] Depew, Creighton A.; and Reisbig, Ronald L.: Vapor Condensation on a Horizontal Tube Using Teflon to Promote Dropwise Condensation. Ind. Eng. Chem., Process Design Develop., vol. 3, no. 4, Oct. 1964 , pp. 365-369.

[8] Topper, Leonard; and Baer, Eric: Dropwise Condensation of Vapors and Heat- Transfer Rates. J. Colloid Sci., vol. 10, 1955, pp. 225226. 